\title{
A MODIFIED D NUMBERS METHODOLOGY FOR ENVIRONMENTAL IMPACT ASSESSMENT
}

\author{
Ningkui WANG, Daijun WEI \\ School of Science, Hubei University for Nationalities, Enshi, Hubei, 445000, China
}

Received 03 July 2015; accepted 11 June 2016

\begin{abstract}
Environmental impact assessment (EIA) is usually evaluated by many factors influenced by various kinds of uncertainty or fuzziness. As a result, the key issues of EIA problem are to represent and deal with the uncertain or fuzzy information. $D$ numbers theory, as the extension of Dempster-Shafer theory of evidence, is a desirable tool that can express uncertainty and fuzziness, both complete and incomplete, quantitative or qualitative. However, some shortcomings do exist in $D$ numbers combination process, the commutative property is not well considered when multiple $D$ numbers are combined. Though some attempts have made to solve this problem, the previous method is not appropriate and convenience as more information about the given evaluations represented by $D$ numbers are needed. In this paper, a data-driven $D$ numbers combination rule is proposed, commutative property is well considered in the proposed method. In the combination process, there does not require any new information except the original $D$ numbers. An illustrative example is provided to demonstrate the effectiveness of the method.
\end{abstract}

Keywords: $D$ numbers theory, EIA, decision making, uncertainty, incompleteness, fuzziness.

JEL Classification: C4, Q48, R38.

\section{Introduction}

In the 21th century, environment problems are the hot issues that draw many countries' attention. EIA problem is an identification of many factors involved in both harmful and beneficial about the project should be put into effect or which plan should be chosen in the decision making system.

Some previous studies show the EIA framework has been developed in many fields (De Boer 2003; Lenzen et al. 2003; Dreyer et al. 2006; Wang et al. 2006; Kiliç et al. 2011; Zapp et al. 2012; Sueyoshi, Goto 2012; Bigum et al. 2012; Xu et al. 2014; Jordan et al. 2014; Zavadskas et al. 2015) and many methods are applied in EIA such as Life cycle assessment (Tukker 2000; Riga et al. 2015), group decision-making methods (Rikhtegar et al. 2014) and

Corresponding author Daijun Wei

E-mails: eswdj@163.com,eswdj@hbmy.edu.cn 
so on (Miao et al. 2014; Ma et al. 2014; Ni et al. 2014). In the real world, many potential environment assessment factors cannot be quantified accurately, they are qualitative or linguistic forms which lead to uncertainty, fuzziness and incompleteness. So one key problem in the EIA is to handle various kinds of forms of uncertainty. Up to now, many methods have been used to deal with uncertainty, such as fuzzy set theory (Zadeh 1965; Wood et al. 2007; Zavadskas et al. 2014; Ju, Yoo 2014; Jiang et al. 2015a), rough set (Pawlak, Skowron 2007; Hu, Lu 2009; Morón et al. 2009), uncertain theory (Liu 2014; Ahmadi et al. 2015; Deng 2015b), Dempster-Shafer theory of evidence (Dempster 1967; Shafer 1976; Deng 2015a; Jiang et al. 2015b), D numbers theory (Deng 2012; Deng et al. 2014c) and so on (Zolfani et al. 2013; Rabbani et al. 2014; Kaplinski et al. 2014; Baleženti, T., Baleženti, A. 2014; Akhavan et al. 2015; Su et al. 2015; Deng et al. 2015a; Mardani et al. 2015).

Literature (Wang et al. 2006) applied Dempster-Shafer theory of evidence to EIA to handle various kinds of uncertainty caused by the subjective judgments, the lacking of information and the incapability of experts to give the accurate assessments. Dempster-Shafer theory of evidence is also called the theory of evidence or evidence theory, it can represent uncertainty directly and the Dempster's rule of combination can combine multiple pieces of evidence into one. Because of such advantages, evidence theory has been used in many fields especially in data fusion (Tian et al. 2005; Deng et al. 2011a, 2011b), water assessment (Sadiq et al. 2006; Sueyoshi, Goto 2012), decision making problems (Beynon et al. 2001; Yang, Xu 2002; Taroun, Yang 2011; Fu, Yang 2012; Fu, Chin 2014) and so on (Wei et al. 2013; Liu et al. 2014b; Yager, Alajlan 2015; Deng et al. 2015b). However, in the classical evidence theory, there are some limitations which may hinder its further applications. For example, the concept basic probability assignment (BPA) which is used to represent the uncertainty must be independent, the sum of all the BPA must be equal to 1 and the frame of discernment must be mutually exclusive and collectively exhaustive. These conditions are usually hard to be satisfied in our real lives and these shortcomings have limited the application of evidence theory to a certain degree (Deng 2012; Deng et al. 2014b).

Recently, a new methodology called $D$ numbers theory, which can deal with both the exclusiveness hypothesis and completeness constraint, has been proposed (Deng 2012; Deng et al. 2014c). This theory extends the classical Dempster-Shafer theory. $D$ numbers theory can represent uncertain information effectively and the exclusive property does not need to be satisfied in the frame of discernment, at the same time, completeness constraint is released which means that the overall assessments does not need to be equal to 1 . In the real word, most of the assessment data appears to be incomplete and hardly to be mutually exclusive, these two improvements in the methodology can be greatly beneficial. With these two advantages, $D$ numbers theory has been used in bridge assessment (Deng et al. 2014a), EIA (Deng et al. 2014b), Supplier selection (Deng et al. 2014c) and so on (Deng et al. 2014d; Liu et al. 2014a; Fan et al. 2016).

$D$ numbers theory has some desirable properties. However, commutative property is not well addressed when multiple $D$ numbers get combined. In (Deng et al. 2014b), order variables have been defined for multiple $D$ numbers combination, but this method is not property and convenient for some new information accompany with $D$ numbers should be given before the combination process. In this paper, a new data-driven method to deal 
with $D$ numbers fusion problem is proposed. This method is completely based on the evaluation grades and any other new information about the assessments is not required. Meanwhile, the proposed method has made full use of the information contained in the given $D$ numbers in the combination process. In order to overcome that deficiency, in this paper, a new method based on the overall assessment grades to deal with $D$ numbers fusion problem is proposed.

The rest of the paper is organized as follows. In Section 1, some preliminaries are described in detail. The proposed method based on assessment grade to combine the uncertain data is presented in Section 2. In Section 3, the proposed method for EIA based on $D$ numbers theory is developed to show the effectiveness of the method. Some conclusions are given in the last Section.

\section{Preliminaries}

\subsection{Dempster-Shafer theory of evidence (Dempster 1967; Shafer 1976)}

Many theories have been developed to handle with various kinds of uncertainty with desirable properties. However, there are some drawbacks that cannot be ignored. For example, with the inherent advantage to represent the uncertainty and the ability to combine pieces of information into one final assessment, the Dempster-Shafer theory of evidence has been applied to many fields. In the mathematical framework of evidence theory, the BPA is defined to represent the uncertain information, the problem domain is defined by a frame of discernment which is a finite and mutually exclusive non-empty set, let $2^{\Theta}$ denote the power set of $\Theta$ and each element in the power set $2^{\Theta}$ is called a proposition which can be used to represent the uncertainty, the BPA is a mapping from $2^{\Theta}$ to $[0,1]$ and the follow conditions are satisfied:

$$
m(\varnothing)=0 \quad \text { and } \quad \sum_{A \subseteq \Theta} m(A)=1 .
$$

Each element in the power set $2^{\Theta}$ is a proposition that can represent uncertainty directly because BPA has the ability to represent the belief degree to the composed subset of the element in $\Theta$ rather than the individual subset in $\Theta$. But any element in $\Theta$ must be exclusive that can hardly be satisfied in real life, this shortcoming has limited its application widely. For example, some linguistic assessment grades are given as "very good", "good", "medium", "bad" and "very bad" by human subjectivity judgment. These assessment grades are not mutually exclusive as the intersection is not empty. Dempster-Shafer theory of evidence is limited in this situation which means that we cannot give the BPA as $m$ (very good, good) = $0.1, m$ (medium $)=0.1$. Another shortcoming is that the sum of BPAs must be equal to 1 , but lots of assessments are not given because of uncertainty or lacking of information due to different background. $D$ numbers theory is an extension of Dempster-Shafer theory of evidence. It has overcome the limitations in classical Dempster-Shafer theory of evidence and appears to handle uncertain information effectively.

With two belief structures $m_{1}$ and $m_{2}$, the Dempster's rule of combination denoted as $m=m_{1} \oplus m_{2}$, is defined as follows: 
with

$$
m(A)= \begin{cases}\frac{1}{1-K} \sum_{B \cap C=A} m_{1}(B) m_{2}(C), & A \neq \varnothing ; \\ 0, & A=\varnothing ;\end{cases}
$$

$$
K=\sum_{B \cap C=\varnothing} m_{1}(B) m_{2}(C) .
$$

$\mathrm{K}$ is a normalization constant, it shows the conflict coefficient of two BPAs. DempsterShafer theory of evidence are only available when $K<1$. Dempster's rule of combination is the core of Dempster-Shafer theory of evidence, multiple pieces of BPAs can be combined into one by this rule and commutative and associative properties are satisfied in it.

\section{2. $D$ numbers theory}

Let $\mathrm{U}$ be a finite nonempty set, $D$ numbers is a mapping $D: U \rightarrow[0,1]$, satisfying (Deng 2012; Deng et al. 2014c):

$$
D(\varnothing)=0 \text { and } \sum_{B \subseteq \Omega} D(B) \leq 1,
$$

where $\varnothing$ is an empty set and B is a non-empty subset of $U$. As can be found that the definition of $D$ number is so similar to the definition of BPA in evidence theory. In fact they are different, in $D$ numbers theory, set $U$ is not required to be mutually exclusive, at the same time, the sum of the assessment can be less than 1 in $D$ numbers theory.

An example is given to show the differences, supposing a assessment is conducted and the assessment score is in the interval $[0,100]$, an expert gives his evaluation in the frame of Dempster-Shafer theory as follows:

$$
\begin{aligned}
& m\left(\left\{a_{1}\right\}\right)=0.3 ; \\
& m\left(\left\{a_{2}\right\}\right)=0.5 ; \\
& m\left(\left\{a_{1}, a_{2}, a_{3}\right\}\right)=0.2,
\end{aligned}
$$

where $a_{1}=[1,30], a_{2}=[31,67], a_{3}=[68,100]$ the intersection between $a_{1}, a_{2}$, and $a_{3}$ is the empty set and $\left(a_{1}, a_{2}, a_{3}\right)$ is the frame of discernment in evidence theory, the sum of $m_{i}$ equals to 1 means it is complete. Meanwhile, another expert gives his assessment by $D$ numbers as follows:

$$
\begin{aligned}
& D\left(\left\{b_{1}\right\}\right)=0.3 ; \\
& D\left(\left\{b_{2}\right\}\right)=0.5 ; \\
& D\left(\left\{b_{1}, b_{2}, b_{3}\right\}\right)=0.1,
\end{aligned}
$$

where $b_{1}=[1,30], b_{2}=[25,67], b_{3}=[60,100] b_{1}, b_{2}$, and $b_{3}$ are not mutually exclusive and they are not a frame of discernment. The sum of $D_{i}$ equals to 0.9 , such kind of information is called incomplete information.

Definition 1. For a discrete set $U=\left(b_{1}, b_{2}, b_{3} \cdots b_{n}\right)$ where $b_{i}$ belongs to $U$ and $b_{i} \neq b_{j}$ if $i \neq j$, for any $v_{i} \geq 0$ and $\sum_{i=1}^{n} v_{i}=1$, a special form of $D$ numbers can be expressed by: 
or be represented simply as:

$$
\begin{gathered}
D\left(\left\{b_{1}\right\}\right)=v_{1} ; \\
D\left(\left\{b_{2}\right\}\right)=v_{2} ; \\
\ldots \\
D\left(\left\{b_{n}\right\}\right)=v_{n}
\end{gathered}
$$

$$
D=\left\{\left(b_{1}, v_{1}\right)\left(b_{2}, v_{2}\right)\left(b_{3}, v_{3}\right) \ldots\left(b_{n}, v_{n}\right)\right\} .
$$

Definition 2. For a given $D$ number, the overall assessment can be calculated as:

$$
I(D)=\sum_{i=1}^{n} b_{i} v_{i}
$$

Definition 3. Let $D_{1}$ and $D_{2}$ be two $D$ numbers,

$$
\begin{aligned}
& D_{1}=\left\{\left(b_{1}^{1}, v_{1}^{1}\right)\left(b_{2}^{1}, v_{2}^{1}\right)\left(b_{3}^{1}, v_{3}^{1}\right) \ldots\left(b_{n}^{1}, v_{n}^{1}\right)\right\} \\
& D_{2}=\left\{\left(b_{1}^{2}, v_{1}^{2}\right)\left(b_{2}^{2}, v_{2}^{2}\right)\left(b_{3}^{2}, v_{3}^{2}\right) \ldots\left(b_{m}^{2}, v_{m}^{2}\right)\right\}
\end{aligned}
$$

the combination of $D_{1}$ and $D_{2}$ denoted by $D=D_{1} \oplus D_{2}$, defined as:

$$
D(b)=v
$$

with

$$
\begin{gathered}
b=\frac{b_{i}^{1}+b_{j}^{2}}{2} ; \\
v=\frac{v_{i}^{1}+v_{j}^{2}}{2 \times c},
\end{gathered}
$$

where

$$
c= \begin{cases}\sum_{j=1}^{m} \sum_{i=1}^{n} \frac{v_{i}^{1}+v_{j}^{2}}{2} & \sum_{i=1}^{n} v_{i}^{1}=1 ; \sum_{j=1}^{m} v_{j}^{2}=1 ; \\ \sum_{j=1}^{m} \sum_{i=1}^{n} \frac{v_{i}^{1}+v_{j}^{2}}{2}+\sum_{j=1}^{m} \frac{v_{c}^{1}+v_{j}^{2}}{2} & \sum_{i=1}^{n} v_{i}^{1}<1 ; \sum_{j=1}^{m} v_{j}^{2}=1 ; \\ \sum_{j=1}^{m} \sum_{i=1}^{n} \frac{v_{i}^{1}+v_{j}^{2}}{2}+\sum_{i=1}^{n} \frac{v_{i}^{1}+v_{c}^{2}}{2} & \sum_{i=1}^{n} v_{i}^{1}=1 ; \sum_{j=1}^{m} v_{j}^{2}<1 ; \\ \sum_{j=1}^{m} \sum_{i=1}^{n} \frac{v_{i}^{1}+v_{j}^{2}}{2}+\sum_{j=1}^{m} \frac{v_{c}^{1}+v_{j}^{2}}{2}+\sum_{i=1}^{n} \frac{v_{i}^{1}+v_{c}^{2}}{2} & \sum_{i=1}^{n} v_{i}^{1}<1 ; \sum_{j=1}^{m} v_{j}^{2}<1,\end{cases}
$$

where $v_{c}^{1}=1-\sum_{i=1}^{n} v_{i}^{1}$ and $v_{c}^{2}=1-\sum_{j=1}^{m} v_{j}^{2}$, the superscript in above equation is not the exponent but the order of the $D$ numbers.

For example, if there are two $D$ numbers, one is complete while another is incomplete.

$$
\begin{aligned}
& D_{1}=\{(1,0.6),(2,0.4)\} ; \\
& D_{2}=\{(3,0.5),(4,0.4)\} .
\end{aligned}
$$


Eqs (6)-(9) are used for the combination of $D_{1}$ and $D_{2}$ and the result is:

$$
D=\{(2,0.22),(2.5,0.38),(3,0.16)\} .
$$

Note that the associative property is not satisfied in the $D$ numbers combine rule. Let $D_{1}, D_{2}$ and $D_{3}$ be three $D$ numbers, where:

The combination results of

$$
\begin{aligned}
& D_{1}=\{(1,0.6),(2,0.4)\} ; \\
& D_{2}=\{(3,0.5),(4,0.4)\} ; \\
& D_{3}=\{(2,1)\} .
\end{aligned}
$$

$$
\begin{aligned}
& D_{123}=D_{1} \oplus D_{2} \oplus D_{3} ; \\
& D_{132}=D_{1} \oplus D_{3} \oplus D_{2} ; \\
& D_{231}=D_{2} \oplus D_{3} \oplus D_{1}
\end{aligned}
$$

are shown below respectively,

$$
\begin{aligned}
& D_{123}=\left\{\left(2, \frac{6.1}{25}\right),\left(2.25, \frac{6.9}{25}\right),\left(2.5, \frac{5.8}{25}\right)\right\} \\
& D_{132}=\left\{\left(2.25, \frac{1.0333}{5}\right),\left(2.5, \frac{0.9667}{5}\right),\left(2.75, \frac{0.93333}{5}\right),\left(3, \frac{0.8667}{5}\right)\right\} \\
& D_{231}=\left\{\left(1.85, \frac{0.975}{5}\right),\left(2.00, \frac{0.95}{5}\right),\left(2.25, \frac{0.775}{5}\right),\left(2.5, \frac{0.75}{5}\right)\right\}
\end{aligned}
$$

Note that $D_{123} \neq D_{132} \neq D_{231}$, these three combination results are different from each other, the sequence has great influence on the final result. In literature (Deng et al. 2014b), an order variable is defined to deal with this problem and put that method in EIA, the expert's weight is regard as the order variable. In the real circumstance, deciding the weight of the knowledge experts will involves in various kinds of subjectivity and it is so hard to decide the weight of every decision maker. So finding out a subjective way for the order variable of the combination is necessary.

\section{Proposed method}

In order to fuse multiple $D$ numbers correctly and efficiently, a subjective method based on evaluation grades which is called "positive-negative method" is proposed. In the decision making system, any human assessments represented by $D$ numbers, $b_{i}$ reflects the evaluation grade. The higher the value of $b_{i}$ is, the more positive the experts have assessed on the object. On the contrary, the experts are not confident about the attribute of the object.

When multiple $D$ numbers get combined, half of the first two $D$ numbers contribute to the second combined results by Eq. (7). Then when the combined results are fused with the third $D$ numbers, half of both the combined results and the third $D$ numbers contribute to the second combined results by Eq. (7). It is to say, the final combined results consist of a quarter of the first two $D$ numbers and half of the third one. Namely, the $D$ numbers combined ahead contribute less and the latter ones are more influential for the final com- 
bined assessments. So in the positive method, the higher assessments are more contributive to the final assessments and those $D$ numbers with higher average assessments should be fused latter than those of lower average assessments. Similarly, the lower assessments are more influential to the final combined results and those $D$ numbers need to be fused after the better assessments are combined in the negative methods. Here the positive-negative method is detail described step by step.

Step 1: For two given $D$ numbers, if they are completely same, which means that two experts gave the same evaluation on the same problem, they need to be fused firstly and the combination result should be the same as the original $D$ numbers. Let $D_{1}$ and $D_{2}$ be two $D$ numbers:

$$
\begin{gathered}
\left\{\begin{array}{c}
D_{1}=\left\{\left(b_{1}^{1}, v_{1}^{1}\right)\left(b_{2}^{1}, v_{2}^{1}\right)\left(b_{3}^{1}, v_{3}^{1}\right) \ldots\left(b_{n}^{1}, v_{n}^{1}\right)\right\} \\
D_{2}=\left\{\left(b_{1}^{2}, v_{1}^{2}\right)\left(b_{2}^{2}, v_{2}^{2}\right)\left(b_{3}^{2}, v_{3}^{2}\right) \ldots\left(b_{n}^{2}, v_{n}^{2}\right)\right\}
\end{array}\right. \\
b_{i}^{1}=b_{j}^{2}(i=j) \text { and } v_{i}^{1}=v_{j}^{2}(i=j) .
\end{gathered}
$$

$D_{1}$ and $D_{2}$ are completely the same, they should be combined firstly, $D$ is the combined result of the two $D$ numbers,

$$
D=D_{1} \oplus D_{2}=D_{1}=D_{2} .
$$

Step 2: When two $D$ numbers are different from each other, the first step is to find the maximum average value $\bar{b}_{i}$, the average value of $D$ number shows the average assessment about the problem. Let $D_{1}, D_{2} \ldots D_{n}$ be $\mathrm{n} D$ numbers:

$$
\left\{\begin{array}{c}
D_{1}=\left\{\left(b_{1}^{1}, v_{1}^{1}\right)\left(b_{2}^{1}, v_{2}^{1}\right)\left(b_{3}^{1}, v_{3}^{1}\right) \ldots\left(b_{r}^{1}, v_{r}^{1}\right)\right\} \\
D_{2}=\left\{\left(b_{1}^{2}, v_{1}^{2}\right)\left(b_{2}^{2}, v_{2}^{2}\right)\left(b_{3}^{2}, v_{3}^{2}\right) \ldots\left(b_{s}^{2}, v_{s}^{2}\right)\right\} \\
\ldots . \\
D_{n}=\left\{\left(b_{1}^{n}, v_{1}^{n}\right)\left(b_{2}^{n}, v_{2}^{n}\right)\left(b_{3}^{n}, v_{3}^{n}\right) \ldots\left(b_{t}^{n}, v_{t}^{n}\right)\right\}
\end{array}\right.
$$

then, the average value $\overline{b_{i}}$ can be calculated as follows:

$$
\left\{\begin{array}{c}
\overline{b_{1}}=\frac{b_{1}^{1}+b_{2}^{1}+b_{3}^{1}+\cdots b_{r}^{1}}{r} \\
\overline{b_{2}}=\frac{b_{1}^{2}+b_{2}^{2}+b_{3}^{2}+\cdots b_{s}^{2}}{s} \\
\cdots \\
\overline{b_{n}}=\frac{b_{1}^{n}+b_{2}^{n}+b_{3}^{n}+\cdots b_{t}^{n}}{t}
\end{array},\right.
$$

where $\overline{b_{i}}$ is the average assessment. Then the combination operation of multiple $D$ numbers is a mapping $f_{D}$, such that:

$$
\left.f_{D}\left(D_{1}, D_{2}, D_{3} \ldots D_{n}\right)=\left[\cdots\left[D_{i} \oplus D_{j}\right] \oplus D_{k}\right] \cdots\right],
$$

where $\overline{b_{i}}<\overline{b_{j}}<\overline{b_{k}}$ in positive method and $\overline{b_{i}}>\overline{b_{j}}>\overline{b_{k}}$ in negative method, $\overline{b_{i}}, \overline{b_{j}}$ and $\overline{b_{k}}$ are corresponding to the average value $D_{i}, D_{j}$ and $D_{k}$. 
Let $D_{i}, D_{j}$ and $D_{k}$ be three $D$ numbers,

$$
\begin{array}{ll}
D_{1}=\{(0,0.6),(1,0.4)\}, & \overline{b_{1}}=0.5 ; \\
D_{2}=\{(1,0.5),(2,0.5)\}, & \overline{b_{2}}=1.5 ; \\
D_{3}=\{(1,1)\}, \quad \overline{b_{3}}=1 &
\end{array}
$$

then in positive method, the combination is $D_{1} \oplus D_{3} \oplus D_{2}$, in negative method, the combination is $D_{3} \oplus D_{2} \oplus D_{1}$.

Step 3: When the average assessments are the same, we need to find out the maximum value of confidence to the assessment grade. The higher value of the average assessment is combined later in the positive method and combined firstly in the negative method.

For example, $D_{1}, D_{2}$ and $D_{3}$ are three $D$ numbers,

$$
\begin{aligned}
& D_{1}=\{(0,0.6),(2,0.4)\}, \overline{b_{1}}=1 ; \\
& D_{2}=\{(1,0.5),(2,0.5)\}, \overline{b_{2}}=1.5 ; \\
& D_{3}=\{(1,1)\}, \overline{b_{3}}=1 .
\end{aligned}
$$

We find that $\overline{b_{1}}=\overline{b_{3}}=1$. Then we should calculate the maximum value of $V_{i}$ of each $D$ numbers.

$$
\begin{aligned}
& D_{1}=\{(0,0.6),(2,0.4)\}, \overline{b_{1}}=1, \max \left(V_{1}\right)=0.6 ; \\
& D_{2}=\{(1,0.5),(2,0.5)\}, \overline{b_{2}}=1.5 ; \\
& D_{3}=\{(1,1)\}, \overline{b_{3}}=1, \quad \max \left(V_{3}\right)=1,
\end{aligned}
$$

then in positive method, the combination process is $D_{1} \oplus D_{3} \oplus D_{2}$ and $D_{2} \oplus D_{1} \oplus D_{3}$ in negative method.

The process of combining multiple $D$ numbers is described in Figure 1.

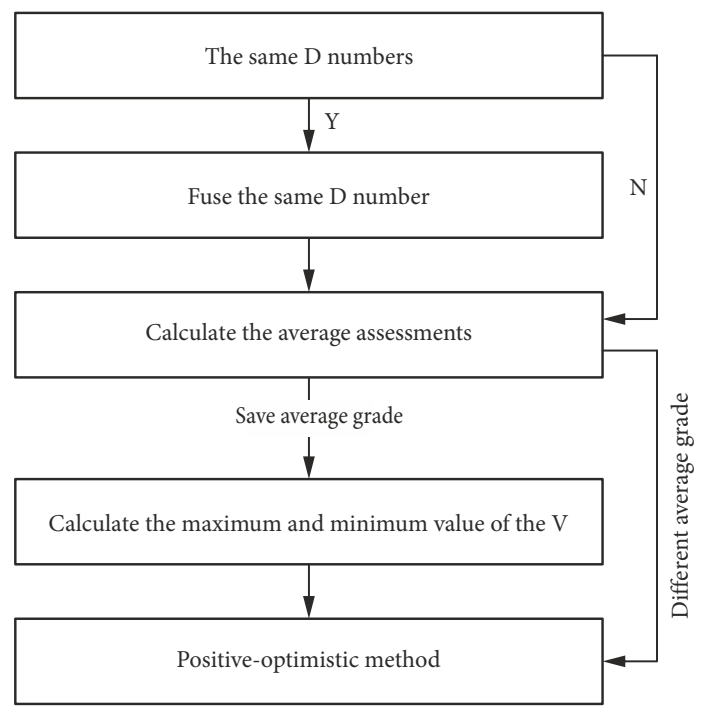

Fig. 1. Multiple $D$ numbers combination 


\section{Examples and applications}

In this section, the proposed method will be adopted to the EIA, meanwhile, the results obtained by the proposed method are compared with the other methods to show the effectiveness of the proposed method.

Generally, four phases are necessary in EIA. Firstly the hierarchical structure model for assessment needs to be established. In this phase, some affect factors that influence the EIA problem need to be identified carefully. Usually these factors can be classified into two parts, the natural factors and the man-made factors (Canter 1996), some necessary work should be done to insure that all the influence factors are included in the primary factors. Then the assessments for each environmental impact factors need to be given by the knowledgeable expert. The third step is the calculation of all the evaluated factors and the last step is to rank the entire project. Here the initial environmental assessment to Rupa Tal Lake is re-investigated as an example to demonstrate the efficiently of the proposed $D$ numbers combination method (Pastakia, Jensen 1998). Some description and evaluation are mainly based on the published work by Refs. (Pastakia, Jensen 1998).

Rupa Tal is a hot tourism of Nepal and provides substantial incomes. In recent years, lake is undergoing sedimentation at a rapid rate. Four projects are considered for conservation of the lake area:

- project 1: No action. The present sedimentation is allowed to continue, so that the lake is disappearing completely and a small gorge is created to take the inflow/outflow streams.

- project 2: Along the southern margin, a high retaining dam is built to raise the overall water level. Due to the build of retaining dam, the in-lake areas created by sedimentation over the last few decades would be inundated.

- project 3: A smaller, high dam is built between two bluffs, it would be about one third of the way up from the southern shore. This partial dam is smaller than that built in project 2 but has similar upstream effects.

- project 4: A single large sedimentation reservoir in the upstream area, or a series of smaller retaining walls, would be used to form a sedimentation cascade. By carrying on this option, the water area may be remaining intact.

In order to assess these four projects, a hierarchical structure model for EIA was established in literature (Wang et al. 2006). From four aspects, it is shown in Figure 2. Each factor has some sub-factors which is detailed in Table 1.

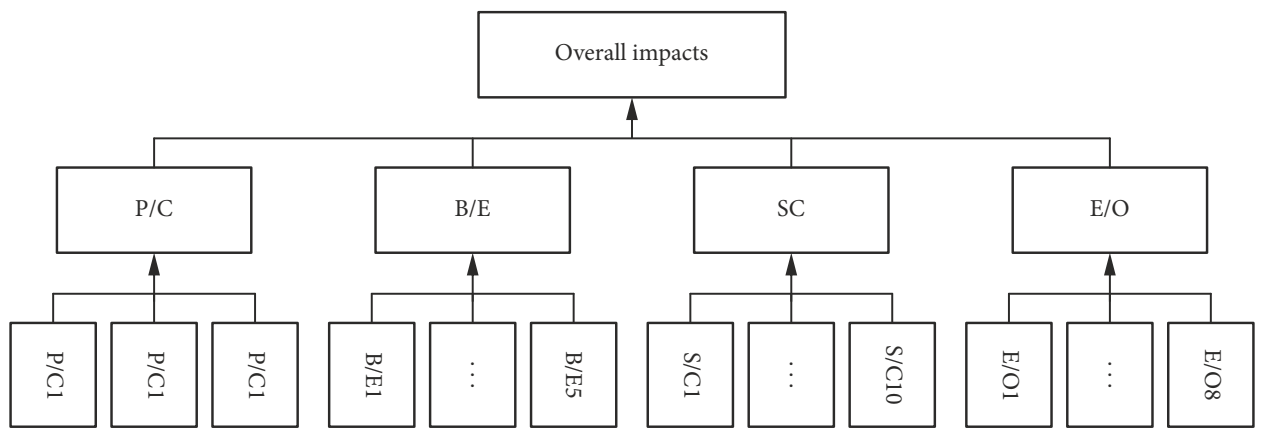

Fig. 2. A hierarchical structure model for EIA 
Table 1. The meanings of factors and sub-factors in EIA (Wang et al. 2006)

\begin{tabular}{|c|c|}
\hline Environmental factors & Sub-factors \\
\hline $\begin{array}{l}\text { Physical/Chemical } \\
(P / C)_{1} \\
(P / C)_{2} \\
(P / C)_{3}\end{array}$ & $\begin{array}{l}\text { The impacts of lake water volume } \\
\text { The impacts of the lake sedimentation } \\
\text { The impacts of crop and grazing areas }\end{array}$ \\
\hline $\begin{array}{l}\text { Biological/Ecological } \\
(B / E)_{1} \\
(B / E)_{2} \\
(B / E)_{3} \\
(B / E)_{4} \\
(B / E)_{5}\end{array}$ & $\begin{array}{l}\text { The impacts of lake fisheries } \\
\text { The impacts of biodiversity } \\
\text { The impacts of primary production } \\
\text { The impacts of aquatic macrophytes } \\
\text { The impacts of disease vector populations }\end{array}$ \\
\hline $\begin{array}{l}\text { Sociological/Culture } \\
(\mathrm{S} / \mathrm{C})_{1} \\
(\mathrm{~S} / \mathrm{C})_{2} \\
(\mathrm{~S} / \mathrm{C})_{3} \\
(\mathrm{~S} / \mathrm{C})_{4} \\
(\mathrm{~S} / \mathrm{C})_{5} \\
(\mathrm{~S} / \mathrm{C})_{6} \\
(\mathrm{~S} / \mathrm{C})_{7} \\
(\mathrm{~S} / \mathrm{C})_{8} \\
(\mathrm{~S} / \mathrm{C})_{9} \\
(\mathrm{~S} / \mathrm{C})_{10}\end{array}$ & $\begin{array}{l}\text { The loss of housing } \\
\text { The loss of shops/public buildings } \\
\text { The impacts of accessing routes } \\
\text { The impacts induced by changes of tourism patterns } \\
\text { The impacts of water supplies } \\
\text { The impacts of diet/nutrition } \\
\text { The impacts of aesthetic landscapes } \\
\text { The impacts of water/vector borne disease } \\
\text { The impacts of upstream quality of life } \\
\text { The impacts of downstream quality of life }\end{array}$ \\
\hline $\begin{array}{l}\text { Economical/Operational } \\
(E / O)_{1} \\
(E / O)_{2} \\
(E / O)_{3} \\
(E / O)_{4} \\
(E / O)_{5} \\
(E / O)_{6} \\
(E / O)_{7} \\
(E / O)_{8}\end{array}$ & $\begin{array}{l}\text { The impacts of crop-generated incomes } \\
\text { The impacts of fishery generated incomes } \\
\text { The convenience of operation and Maintenance of option } \\
\text { The cost of operation and Maintenance of option } \\
\text { The cost of resettlement and compensation for land loss } \\
\text { The cost of rehabilitation } \\
\text { The cost of restoration of accessing routes } \\
\text { The impacts of tourism-generated incomes }\end{array}$ \\
\hline
\end{tabular}

Every sub-factor has different influence on the assessment of the projects. So at second the calculation of the assessment should be done. Nevertheless most of the assessments are represented by linguistic grades such as "good" and "poor", "A", "B", "C" and so forth. First of all, translating such assessment into numerical grade is so necessary. In the existing literature (Khan, Fitzcharles 1998), a seven points scale from " -3 ” to “ +3 ” was used to represent the impacts from "High influence" to "low influence", in Ref. (Pun et al. 2003), the

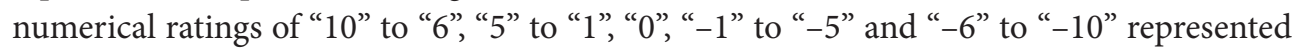
five grades from "very high impact" to "very low impact" respectively. In general terms, the translating level is different from specific problems. Literature (Wang et al. 2006), translated the original grades " $\mathrm{A}$ ", "B", "C" and so on into numerical grades which are shown in Table 2 so that $D$ numbers theory can deal with such kinds of uncertainty. For example, when ten experts give the assessments for the conservation of the Rupa Tal, four experts believe it is major positive impacts and the other six evaluate it to be Moderately positive impact, then $D$ numbers should be $\{(5,0.4)(3,0.6)\}$, this information is complete because all experts have given their opinions. Another five experts assess it to be positive impact while two experts 
evaluate it to be no impact, the left experts don't give any evaluation because of lacking of information, the $D$ numbers can be $\{(2,0.5),(0,0.2)\}$. This kind of information is said to be incomplete. Table 3 shows the assessment matrixes.

Table 2. An assessment standard for EIA (Pastakia, Jensen 1998; Wang et al. 2006)

\begin{tabular}{ccl}
\hline Assessment grade & Numerical rating & \multicolumn{1}{c}{ Description } \\
\hline E & 5 & Major positive impact \\
D & 4 & Signification positive impact \\
C & 3 & Moderately positive impact \\
B & 2 & Positive impact \\
A & 1 & Slightly impact \\
N & 0 & No impact \\
- A & -1 & Slightly negative impact \\
- B & -2 & Negative impact \\
-C & -3 & Moderately negative impact \\
- D & -4 & Significant negative impact \\
- E & -5 & Major negative impact \\
\hline
\end{tabular}

Table 3. Assessment matrix of environment impact factors (Wang et al. 2006)

\begin{tabular}{|c|c|c|c|c|}
\hline $\begin{array}{l}\text { Environmental } \\
\text { factors }\end{array}$ & Project 1 & Project 2 & Project 3 & Project 4 \\
\hline $\begin{array}{l}\text { Physical/Chemical } \\
(P / C)_{1} \\
(P / C)_{2} \\
(P / C)_{3}\end{array}$ & $\begin{array}{l}\{(-4,0.3),(-3,0.7)\} \\
\{(-2,0.8),(-1,0.2)\} \\
\{(2,0.45),(3,0.35)\}\end{array}$ & $\begin{array}{c}\{(1,0.1),(2,0.9)\} \\
\{(1,0.1),(2,0.85)\} \\
\{(-3,0.2),(-2,0.8)\}\end{array}$ & $\begin{array}{c}\{(2,0.8),(3,0.2)\} \\
\{(-1,0.85),(3,0.15\} \\
\{(0,0.5),(1,0.5)\}\end{array}$ & $\begin{array}{c}\{(0,1)\} \\
\{(1,0.3),(2,0.7)\} \\
\{(0,1)\}\end{array}$ \\
\hline $\begin{array}{l}\text { Biological/Ecological } \\
(B / E)_{1} \\
(B / E)_{2} \\
(B / E)_{3} \\
(B / E)_{4} \\
(B / E)_{5}\end{array}$ & $\begin{array}{c}\{(-3,0.5),(-2,0.4)\} \\
\{(-2,0.5)(-1,0.5)\} \\
\{(-2,0.8)(-1,1.0)\} \\
\{(-2,0.1)\} \\
\quad\{(-2,0.1)\}\end{array}$ & $\begin{array}{l}\{(-2,1.0)\} \\
\{(-2,1.0)\} \\
\{(-2,1.0)\}\end{array}$ & $\begin{array}{c}\{(0,0.2),(1,0.8)\} \\
\{(-1,1.0)\} \\
\{(-1,1.0)\} \\
\{(-1,1.0)\} \\
\{(1,1.0)\} \\
\end{array}$ & $\begin{array}{c}\{(0,1)\} \\
\{(0,1)\} \\
\{(0,1)\} \\
\{(0,1)\} \\
\{(-1,0.4),(0,0.5\}\end{array}$ \\
\hline $\begin{array}{l}\text { Sociological/Culture } \\
(\mathrm{S} / \mathrm{C})_{1} \\
(\mathrm{~S} / \mathrm{C})_{2} \\
(\mathrm{~S} / \mathrm{C})_{3} \\
(\mathrm{~S} / \mathrm{C})_{4} \\
(\mathrm{~S} / \mathrm{C})_{5} \\
(\mathrm{~S} / \mathrm{C})_{6} \\
(\mathrm{~S} / \mathrm{C})_{7} \\
(\mathrm{~S} / \mathrm{C})_{8} \\
(\mathrm{~S} / \mathrm{C})_{9} \\
(\mathrm{~S} / \mathrm{C})_{10}\end{array}$ & $\begin{array}{c}\{(0,1.0)\} \\
\{(0,1.0)\} \\
\{(1,0.5),(2,0.5)\} \\
\{(-2,0.2)(1,0.8)\} \\
\{(-2,0.3)(1,0.7)\} \\
\{(0,1.0)\} \\
\{(-2,1.0)\} \\
\{(1,0.5)(2,0.3)\} \\
\{(0,1.0)\} \\
\{(-1,1.0)\}\end{array}$ & $\begin{array}{c}\{(-1,1.0)\} \\
\{(-1,0.65),(0,0.03)\} \\
\{(-1,1.0)\} \\
\{(2,0.8),(3,0.2)\} \\
\{(3,1.0)\} \\
\{(1,0.8),(2,0.2)\} \\
\{(2,1.0)\} \\
\{(-1,1.0)\} \\
\{(1,1.0)\} \\
\{(2,1.0)\}\end{array}$ & $\begin{array}{c}\{(-1,1.0)\} \\
\{(-1,1.0)\} \\
\{(1,1.0)\} \\
\{(1,1.0)\} \\
\{(1,0.5),(2,0.5)\} \\
\{(-1,0.85)(3,0.15)\} \\
\{(1,1.0)\} \\
\{(0,0.2),(1,0.7)\} \\
\{(-2,0.8),(-1,0.2)\}\end{array}$ & $\begin{array}{l}\{(0,1.0)\} \\
\{(0,1.0)\} \\
\{(0,1.0)\} \\
\{(0,1.0)\} \\
\{(1,0.8)\} \\
\{(0,1.0)\} \\
\{(0,1.0)\} \\
\{(-1,1.0)\} \\
\{(-1,1.0)\} \\
\{(0,1.0)\}\end{array}$ \\
\hline $\begin{array}{l}\text { Economical/Operat } \\
(E / O)_{1} \\
(E / O)_{2} \\
(E / O)_{3} \\
(E / O)_{4} \\
(E / O)_{5} \\
(E / O)_{6} \\
(E / O)_{7} \\
(E / O)_{8}\end{array}$ & $\begin{array}{c}\{(2,0.8)\} \\
\{(-2,1.0)\} \\
\{(0,1.0)\} \\
\{(0,1.0)\} \\
\{(0,1.0)\} \\
\{(0,1.0)\} \\
\{(0,1.0)\} \\
\{(-1,1.0)\}\end{array}$ & $\begin{array}{l}\{(-1,1.0)\} \\
\{(2,1.0)\} \\
\{(-1,1.0)\} \\
\{(-1,1.0)\} \\
\{(-1,1.0)\} \\
\{(-1,1.0)\} \\
\{(-1,1.0)\} \\
\{(3,0.7)\}\end{array}$ & $\begin{array}{l}\{(-2,0.9)\} \\
\{(0,1.0)\} \\
\{(-1,1.0)\} \\
\{(-2,1.0)\} \\
\{(-1,1.0)\} \\
\{(-1,1.0)\} \\
\{(-1,1.0)\} \\
\{(1,1.0)\}\end{array}$ & $\begin{array}{l}\{(0,1.0)\} \\
\{(0,1.0)\} \\
\{(-2,1.0)\} \\
\{(-1,1.0)\} \\
\{(0,1.0)\} \\
\{(0,1.0)\} \\
\{(0,1.0)\} \\
\{(0,1.0)\}\end{array}$ \\
\hline
\end{tabular}


The third step is to calculate the overall assessment for different projects. It is based on the Eqs (5)-(14). For example, for the evaluation of project 3, the environmental factors are physical and chemical. With respect to primacy $(\mathrm{P} / \mathrm{C})_{1}$, the assessment is $\{(2,0.8),(3,0.2)\}$, for sub-factor $(\mathrm{P} / \mathrm{C})_{2}$, the assessed is $\{(-1,0.85)(0,0.15)\}$. the assessment $\{(0,0.5),(1,0.5)\}$ to the sub-factor $(\mathrm{P} / \mathrm{C})_{3}$. Firstly, the average assessment grades should be obtained:

$$
(\mathrm{P} / \mathrm{C})_{1}: 2.5 ;(\mathrm{P} / \mathrm{C})_{2}:-0.5 ;(\mathrm{P} / \mathrm{C})_{3}: 0.5
$$

then with the positive method, the fusion should be

$$
(P / C)_{2} \oplus(P / C)_{3} \oplus(P / C)_{1}
$$

the result is:

$$
\left\{\left(0.75, \frac{1.1375}{5}\right),\left(1, \frac{1.3}{5}\right),\left(1.25, \frac{1.50}{5}\right),\left(1.5, \frac{0.7}{5}\right),\left(1.75, \frac{0.3625}{5}\right)\right\}
$$

with the negative method, the fusion should be

$$
(P / C)_{1} \oplus(P / C)_{3} \oplus(P / C)_{2}
$$

and the combined result is:

$$
\left\{\left(0, \frac{1.175}{5}\right),\left(0.25, \frac{1.35}{5}\right),\left(0.5, \frac{1.50}{5}\right),\left(0.75, \frac{0.65}{5}\right),\left(1, \frac{0.325}{5}\right)\right\} .
$$

By using the same method, the overall assessment results are calculated. And the last step is to rank all projects according to the values of integration representation of projects' overall value. By Eq. (5), the last score can be calculated. Table 4 shows the final results and ranking by both positive and negative method.

In order to show the effective of the proposed method, the results obtained by the proposed method is combined with the previous methods which are shown in Table 5. As is shown, In literature (Wang et al. 2006), the ranking is project $2>$ project $4>$ project 3 $>$ project 1 for a risk-neutral decision maker. project $2>$ project $3>$ project $4>$ project 1 for a risk-taking decision maker and project $4>$ project $2>$ project $3>$ project 1 for a riskaverse decision maker. Anyhow, project 1 is always the worst choice, project 2 and project 4 are tend to be chosen.

Table 4. Overall environmental impacts and ranking of each project

\begin{tabular}{lcc}
\hline \multicolumn{1}{c}{ Assessment grade } & Impact rating & Ranking \\
\hline Positive method & & \\
Project 1 & 0.1224 & 4 \\
Project 2 & 0.9167 & 2 \\
Project 3 & 0.9275 & 1 \\
Project 4 & 0.1615 & 3 \\
Negative method & & \\
Project 1 & -1.1408 & 4 \\
Project 2 & -0.5906 & 2 \\
Project 3 & -0.0766 & 1 \\
Project 4 & -0.3152 & 3 \\
\hline
\end{tabular}


Table 5. Overall environmental impacts and ranking of each project

\begin{tabular}{ll}
\hline \multicolumn{2}{c}{ Methods Ranking } \\
\hline ER approach & Project $2>$ Project $4>$ Project $3>$ Project 1 \\
Risk-neutral & Project $2>$ Project $3>$ Project $4>$ Project 1 \\
Risk-taking & Project $4>$ Project $2>$ Project $3>$ Project 1 \\
Risk-average & \\
$\begin{array}{l}\text { Deng's method } \\
\text { Decision-optimistic }\end{array}$ & Project $3>$ Project $2>$ Project $4>$ Project 1 \\
$\begin{array}{l}\text { Decision-pessimistic } \\
\text { Proposed method }\end{array}$ & Project $4>$ Project $2>$ Project $3>$ Project 1 \\
Positive-method & Project $3>$ Project $2>$ Project $4>$ Project 1 \\
Negative-method & Project $3>$ Project $2>$ Project $4>$ Project 1 \\
\hline
\end{tabular}

In literature (Deng et al. 2014b), the ranking is project $3>$ project $2>$ project $4>$ project 1 for a decision optimistic maker and project $4>$ project $2>\operatorname{project~} 3>$ project 1 for a decision pessimistic maker.

In this paper, both the positive and negative method shows project $3>$ project $2>$ project $4>$ project 1 . From the comparison of results of different methods, both of them shows project 1 is the worst choice, there is only little differences between the final options. In reference (Wang et al. 2006), the best choice is project 2 or project 4 . In reference (Deng et al. 2014b), the best choice is project 3 or project 4 . In this paper, the best choice is project 3 for both positive and negative method. In the real word, this kind of problem needs further consideration because it is still an open issue and our methods is also reasonable because of the uncertainty of the assessments.

\section{Conclusions}

Most EIA problems contain a lot of human subjective judgments and different kinds of uncertainty, complete or incomplete, quantitative or qualitative. These kinds of information increases the complexity and difficulty of EIA process. So powerful in the methodology and the capacities of dealing with uncertainty are so necessary for EIA problems. $D$ numbers theory provides an ideal, reliable and flexible way for this problem.

$D$ numbers theory, as the extension of Dempster-Shafer theory of evidence, has removed the necessary hypothesis in evidence theory reasonable and it is more powerful when handling the information of both uncertainty and incomplete. However, shortcomings do exist in the $D$ numbers combination rule because commutative property is not well satisfied. In this paper, the proposed method is effective for multiple $D$ numbers combination. In combination process, the same $D$ numbers should be combined firstly. For the left $D$ numbers, the worse average evaluations are combined ahead the better average assessments in the positive method while the better average assessments come first in the negative method. While the average assessments are the same, the confidence degree about the evaluations is taken into consideration. The modified data-driven $D$ numbers combination method proposed in this paper can perfect the $D$ numbers theory itself and can be used in many decision situations such as optimization and so on forth. 
Meanwhile, the proposed $D$ numbers combination rule has many advantages. It is a data-driven method and makes full use of the information contained in the given $D$ numbers in the combination process, no more information about the evaluations denoted by $D$ numbers are needed. At the same time, the proposed combination rule can provide two results for the decision makers from both positive and negative aspects, it is of great use for the decision makers to make the final decision.

In the next step, the proposed method to handle multiple $D$ numbers combination will be extend to handle more uncertain and incomplete problems, such as the risk assessments, water assessments, data fusion and so on. We all believe that the proposed method is powerful and appropriate in these fields.

\section{Acknowledgements}

The work is partially supported by National Natural Science Foundation of China under Grant [number 61364030] and the Training Programs of Innovation and Entrepreneurship for Undergraduates of Hubei Province under Grant [number 201410517018].

\section{References}

Ahmadi, A.; Moridi, A.; Han, D. 2015. Uncertainty assessment in environmental risk through Bayesian networks, Journal of Environmental Informatics 25(1): 46-59. https://doi.org/10.3808/jei.201500294

Akhavan, P.; Barak, S.; Maghsoudlou, H.; Antuchevičiené, J. 2015. FQSPM-SWOT for strategic alliance planning and partner selection; case study in a holding car manufacturer company, Technological and Economic Development of Economy 21(2): 165-185. https://doi.org/10.3846/20294913.2014.965240

Baležentis, T.; Baležentis, A. 2014. A survey on development and applications of the multi-criteria decision making method MULTIMOORA, Journal of Multi-Criteria Decision Analysis 21(3-4): 209-222. https://doi.org/10.1002/mcda.1501

Beynon, M.; Cosker, D.; Marshall, D. 2001. An expert system for multi-criteria decision making using Dempster-Shafer theory, Expert Systems with Applications 20(4): 357-367. https://doi.org/10.1016/S0957-4174(01)00020-3

Bigum, M.; Brogaard, L.; Christensen, T. H. 2012. Metal recovery from high-grade WEEE: a life cycle assessment, Journal of Hazardous Materials 207-208: 8-14. https://doi.org/10.1016/j.jhazmat.2011.10.001

Canter, L. W. 1996. Environmental impact assessment. McGraw-Hill New York.

De Boer, I. J. M. 2003. Environmental impact assessment of conventional and organic milk production, Livestock Production Science 80(1): 69-77. https://doi.org/10.1016/S0301-6226(02)00322-6

Dempster, A. P. 1967. Upper and lower probabilities induced by a multivalued mapping, The Annals of Mathematical Statistics 38(2): 325-339. https://doi.org/10.1214/aoms/1177698950

Deng, X. Y.; Hu, Y.; Deng, Y. 2014a. Bridge condition assessment using D numbers, The Scientific World Journal 2014(5): 1-10.

Deng, X. Y.; Hu, Y.; Deng, Y.; Mahadevan, S. 2014b. Environmental impact assessment based on D numbers, Expert Systems with Applications 41(2): 635-643. https://doi.org/10.1016/j.eswa.2013.07.088

Deng, X. Y.; Hu, Y.; Deng, Y.; Mahadevan, S. 2014c. Supplier selection using AHP methodology extended by D numbers, Expert Systems with Applications 41(1): 156-167. https://doi.org/10.1016/j.eswa.2013.07.018

Deng, X. Y.; Lu, X.; Chan, F. T. S.; Sadiq, R.; Mahadevan, S.; Deng, Y. 2014d. D-CFPR: D numbers extended consistent fuzzy preference relations, Knowledge-Based Systems 73: 61-68.

https://doi.org/10.1016/j.knosys.2014.09.007 
Deng, Y. 2012. D numbers: theory and applications, Journal of Information and Computational Science 9(9): 2421-2428.

Deng, Y. 2015a. Generalized evidence theory, Applied Intelligence 43(3): 530-543. https://doi.org/10.1007/s10489-015-0661-2

Deng, Y. 2015b. A threat assessment model under uncertain environment, Mathematical Problems in Engineering 2015, Article ID 878024. https://doi.org/10.1155/2015/878024

Deng, Y.; Jiang, W.; Sadiq, R. 2011a. Modeling contaminant intrusion in water distribution networks: A new similarity-based DST method, Expert Systems with Applications 38(1): 571-578. https://doi.org/10.1016/j.eswa.2010.07.004

Deng, Y.; Liu, Y.; Zhou, D. Y. 2015a. An improved genetic algorithm with initial population strategy for symmetric TSP, Mathematical Problems in Engineering 2015, Article ID 212794. https://doi.org/10.1155/2015/212794

Deng, Y.; Mahadevan, S.; Zhou, D. Y. 2015b. Vulnerability assessment of physical protection systems: a bio-inspired approach, International Journal of Unconventional Computing 11(3-4): 227-243.

Deng, Y.; Sadiq, R.; Jiang, W.; Tesfamariam, S. 2011b. Risk analysis in a linguistic environment: a fuzzy evidential reasoning-based approach, Expert Systems with Applications 38(12): 15438-15446. https://doi.org/10.1016/j.eswa.2011.06.018

Dreyer, L.; Hauschild, M.; Schierbeck, J. 2006. A framework for social life cycle impact assessment, The International Journal of Life Cycle Assessment 11(2): 88-97. https://doi.org/10.1065/lca2005.08.223

Fan, G. C.; Zhong, D. H.; Yan, F. G.; Yue, P. 2016. A hybrid fuzzy evaluation method for curtain grouting efficiency assessment based on an AHP method extended by D numbers, Expert Systems with Applications 44: 289-303. https://doi.org/10.1016/j.eswa.2015.09.006

Fu, C.; Chin, K. S. 2014. Robust evidential reasoning approach with unknown attribute weights, Knowledge-Based Systems 59: 9-20. https://doi.org/10.1016/j.knosys.2014.01.024

Fu, C.; Yang, S. L. 2012. An evidential reasoning based consensus model for multiple attribute group decision analysis problems with interval-valued group consensus requirements, European Journal of Operational Research 223(1): 167-176. https://doi.org/10.1016/j.ejor.2012.05.048

Hashemkhani Zolfani, S.; Aghdaie, M. H.; Derakhti, A.; Zavadskas, E. K.; Varzandeh, M. H. M. 2013. Decision making on business issues with foresight perspective; an application of new hybrid MCDM model in shopping mall locating, Expert Systems with Applications 40(17): 7111-7121. https://doi.org/10.1016/j.eswa.2013.06.040

$\mathrm{Hu}$, Q. Z.; Lu, H. P. 2009. Rough set comprehensive evaluation model for environmental security effect of highway construction projects, in Energy and Environment Technology 2009 (ICEET'09), 16-18 October 2009, Guilin, China, 301-304.

Jiang, W.; Luo, Y.; Qin, X. Y.; Zhan, J. 2015a. An improved method to rank generalized fuzzy numbers with different left heights and right heights, Journal of Intelligent and Fuzzy Systems 28(5): 2343-2355. https://doi.org/10.3233/IFS-151639

Jiang, W.; Yang, Y.; Luo, Y.; Qin, X. Y. 2015b. Determining basic probability assignment based on the improved similarity measures of generalized fuzzy numbers, International Journal of Computers Communications and Control 10(3): 333-347. https://doi.org/10.15837/ijccc.2015.3.1656

Jordan, Y. C.; Ghulam, A.; Chu, M. L. 2014. Assessing the impacts of future urban development patterns and climate changes on total suspended sediment loading in surface waters using geoinformatics, Journal of Environmental Informatics 24(2): 65-79. https://doi.org/10.3808/jei.201400283

Ju, H. C.; Yoo, S. H. 2014. Using the fuzzy set theory to developing an environmental impact assessment index for a thermal power plant, Quality and Quantity 48(2): 673-680. https://doi.org/10.1007/s11135-012-9794-0

Kaplinski, O.; Peldschus, F.; Tupenaite, L. 2014. Development of MCDM methods-in honour of Professor Edmundas Kazimieras Zavadskas on the occasion of his 70th birthday, International Journal of Computers Communications and Control 9(3): 305-312. https://doi.org/10.15837/ijccc.2014.3.1084

Khan, M.; Fitzcharles, K. 1998. Environmental management field handbook for rural road improvement projects. CARE International Bangladesh, Dhaka. 
Kiliç, E.; Puig, R.; Baquero, G.; Font, J.; Çolak, S.; Gürler, D. 2011. Environmental optimization of chromium recovery from tannery sludge using a life cycle assessment approach, Journal of Hazardous Materials 192(1): 393-401.

Lenzen, M.; Murray, S. A.; Korte, B.; Dey, C. J. 2003. Environmental impact assessment including indirect effects - a case study using input-output analysis, Environmental Impact Assessment Review 23(3): 263-282. https://doi.org/10.1016/S0195-9255(02)00104-X

Liu, B. D. 2014. Uncertainty theory. Springer.

Liu, H. C.; You, J. X.; Fan, X. J.; Lin, Q. L. 2014a. Failure mode and effects analysis using D numbers and grey relational projection method, Expert Systems with Applications 41(10): 4670-4679. https://doi.org/10.1016/j.eswa.2014.01.031

Liu, Z. G.; Pan, Q.; Dezert, J. 2014b. Classification of uncertain and imprecise data based on evidence theory, Neurocomputing 133: 459-470. https://doi.org/10.1016/j.neucom.2013.12.009

Ma, Z. Z.; Wang, Z. J.; Xia, T.; Gippel, C. J.; Speed, R. 2014. Hydrograph-based hydrologic alteration assessment and its application to the yellow river, Journal of Environmental Informatics 23(1): 1-13. https://doi.org/10.3808/jei.201400252

Mardani, A.; Jusoh, A.; Zavadskas, E. K. 2015. Fuzzy multiple criteria decision-making techniques and applications-two decades review from 1994 to 2014, Expert Systems with Applications 42(8): 4126-4148. https://doi.org/10.1016/j.eswa.2015.01.003

Miao, D. Y.; Huang, W. W.; Li, Y. P.; Yang, Z. F. 2014. Planning water resources systems under uncertainty using an interval-fuzzy de novo programming method, Journal of Environmental Informatics 24(1): 11-23. https://doi.org/10.3808/jei.201400277

Morón, A. B.; Calvo-Flores, M. D.; Ramos, J. M.; Almohano, M. P. 2009. AIEIA: Software for fuzzy environmental impact assessment, Expert Systems with Applications 36(5): 9135-9149. https://doi.org/10.1016/j.eswa.2008.12.055

Ni, J. R.; Wu, A.; Li, T. H.; Yue, Y.; Borthwick, A. G. L. 2014. Efficient soil loss assessment for large basins using smart coded polygons, Journal of Environmental Informatics 23(2): 47-57. https://doi.org/10.3808/jei.201400264

Pastakia, C. M.; Jensen, A. 1998. The rapid impact assessment matrix (RIAM) for EIA, Environmental Impact Assessment Review 18(5): 461-482. https://doi.org/10.1016/S0195-9255(98)00018-3

Pawlak, Z; Skowron, A. 2007. Rudiments of rough sets, Information Sciences 177(1): 3-27. https://doi.org/10.1016/j.ins.2006.06.003

Pun, K. F.; Hui, I. K.; Lewis, W. G.; Lau, H. C. 2003. A multiple-criteria environmental impact assessment for the plastic injection molding process: a methodology, Journal of Cleaner Production 11(1): 41-49. https://doi.org/10.1016/S0959-6526(02)00019-7

Rabbani, A.; Zamani, M.; Yazdani-Chamzini, A.; Zavadskas, E. K. 2014. Proposing a new integrated model based on sustainability balanced scorecard (SBSC) and MCDM approaches by using linguistic variables for the performance evaluation of oil producing companies, Expert Systems with Applications 41(16): 7316-7327. https://doi.org/10.1016/j.eswa.2014.05.023

Riga, M.; Stocker, M.; Rönkkö, M.; Karatzas, K.; Kolehmainen, M. 2015. Atmospheric environment and quality of life information extraction from twitter with the use of self-organizing maps, Journal of Environmental Informatics 26(1): 27-40.

Rikhtegar, N.; Mansouri, N.; Oroumieh, A. A.; Yazdani-Ccamzini, A.; Zavadskas, E. K.; Kildienè, S.; 2014. Environmental impact assessment based on group decision-making methods in mining projects, Economic Research-Ekonomska Istraživanja 27(1): 378-392. https://doi.org/10.1080/1331677X.2014.966971

Sadiq, R.; Kleiner, Y.; Rajani, B. 2006. Estimating risk of contaminant intrusion in water distribution networks using Dempster-Shafer theory of evidence, Civil Engineering and Environmental Systems 23(3): 129-141. https://doi.org/10.1080/10286600600789276

Shafer, G. 1976. A mathematical theory of evidence. Princeton University Press. 
Su, X. Y.; Mahadevan, S.; Xu, P. D.; Deng, Y. 2015. Dependence assessment in human reliability analysis using evidence theory and AHP, Risk Analysis 35(7): 1296-1316. https://doi.org/10.1111/risa.12347

Sueyoshi, T.; Goto, M. 2012. Data envelopment analysis for environmental assessment: comparison between public and private ownership in petroleum industry, European Journal of Operational Research 216(3): 668-678. https://doi.org/10.1016/j.ejor.2011.07.046

Taroun, A.; Yang, J. B. 2011. Dempster-shafer theory of evidence: potential usage for decision making and risk analysis in construction project management, The Built and Human Environment Review 4(1): 155-166.

Tian, J. F.; Zhao, W. D.; Du, R. Z.; Zhang, Z. 2005. D-S evidence theory and its data fusion application in intrusion detection, in Parallel and Distributed Computing, Applications and Technologies 2005(PDCAT 2005), 5-8 December 2005, Dalian, China, 115-119.

Tukker, A. 2000. Life cycle assessment as a tool in environmental impact assessment, Environmental Impact Assessment Review 20(4): 435-456. https://doi.org/10.1016/S0195-9255(99)00045-1

Wang, Y. M.; Yang, J. B.; Xu, D. L. 2006. Environmental impact assessment using the evidential reasoning approach, European Journal of Operational Research 174(3): 1885-1913. https://doi.org/10.1016/j.ejor.2004.09.059

Wei, D. J.; Deng, X. Y.; Zhang, X. G.; Deng, Y.; Mahadevan, S. 2013. Identifying influential nodes in weighted networks based on evidence theory, Physica A: Statistical Mechanics and its Applications 392(10): 2564-2575.

Wood, G.; Rodriguez-Bachiller, A.; Becker, J. 2007. Fuzzy sets and simulated environmental change: evaluating and communicating impact significance in environmental impact assessment, Environment and Planning A 39(4): 810-829. https://doi.org/10.1068/a3878

Xu, Y.; Huang, G. H.; Cheng, G. H.; Liu, Y.; Li, Y. F. 2014. A two-stage fuzzy chance-constrained model for solid waste allocation planning, Journal of Environmental Informatics 24(2): 101-110. https://doi.org/10.3808/jei.201400261

Yager, R. R.; Alajlan, N. 2015. Dempster-Shafer belief structures for decision making under uncertainty, Knowledge-Based Systems 80: 58-66. https://doi.org/10.1016/j.knosys.2014.12.031

Yang, J. B.; Xu, D. L. 2002. On the evidential reasoning algorithm for multiple attribute decision analysis under uncertainty, IEEE Transactions on Systems, Man, and Cybernetics - Part A: Systems and Humans 32(3): 289-304. https://doi.org/10.1109/TSMCA.2002.802746

Zadeh, L. A. 1965. Fuzzy sets, Information and Control 8(3): 338-353. https://doi.org/10.1016/S0019-9958(65)90241-X

Zapp, P.; Schreiber, A.; Marx, J.; Haines, M.; Hake, J. F.; Gale, J. 2012. Overall environmental impacts of CCS technologies - a life cycle approach, International Journal of Greenhouse Gas Control 8: 12-21. https://doi.org/10.1016/j.ijggc.2012.01.014

Zavadskas, E. K.; Antucheviciene, J.; Hajiagha, S. H. R.; Hashemi, S. S. 2014. Extension of weighted aggregated sum product assessment with interval-valued intuitionistic fuzzy numbers (WASPASIVIF), Applied Soft Computing 24: 1013-1021. https://doi.org/10.1016/j.asoc.2014.08.031

Zavadskas, E. K.; Turskis, Z.; Bagočius, V. 2015. Multi-criteria selection of a deep-water port in the eastern baltic sea, Applied Soft Computing 26: 180-192. https://doi.org/10.1016/j.asoc.2014.09.019

Ningkui WANG. Master student, Hubei University for Nationalities, Hubei, China. Research interests: multiple criteria decision making and optimization algorithms.

Daijun WEI. Doctor, Associated Professor at the School of Science of Hubei University for Nationalities. He received the M.S. and PhD degrees in 2008 and 2014, respectively, from Central China Normal University and Southwest University. Author and co-author of more than 30 scientific articles. Research interests: fuzzy system, multiple criteria decision making, optimizing control system, complex networks. 